\title{
INVESTIGAÇ̃̃O EXPERIMENTAL E MODELAGEM DA DISPERSÃO UTILIZANDO FIRE DYNAMICS SIMULATOR (FDS) PARA UM VAZAMENTO ACIDENTAL DE GLP
}

\author{
EXPERIMENTAL INVESTIGATION AND DISPERSION MODELING OF FIRE \\ DYNAMIC SIMULATOR USING (FDS) FOR AN ACCIDENTAL LEAKAGE OF LPG
}

\author{
Igor Olímpio Pazini da Cunha ${ }^{1}$ \\ André Pimentel Lugon ${ }^{2}$ \\ Bruno Moreira Bona ${ }^{3}$
}

Resumo

O gás liquefeito de petróleo (GLP) é uma mistura de propano e butano, sendo um importante combustível para o funcionamento de sistemas de aquecimento e em fornos residenciais e industriais para cocção de alimentos. O objetivo deste trabalho foi realizar um estudo de caso de uma explosão ocorrida no município de Vila Velha/ ES, no dia 31 de maio de 2018. Para isso foi construído um modelo computacional, utilizando-se o software Fire Dynamics Simulator, realizando medidas da concentração do gás na região da possível fonte de ignição que provocou a explosão. Resultados demonstraram que com a dispersão do GLP presente na botija, em um tempo de aproximadamente 1 hora e 40 minutos com um fluxo de massa de $0,0007142857 \mathrm{~kg} / \mathrm{s}$ durante uma simulação de 14.400 segundo (4 horas), na altura do interruptor acionado antes da explosão, a concentração do GLP foi registrada em 2,0\%, situando-se dentro dos limites de explosividade do GLP, reforçando a hipótese de causa acidental.

Palavras-chave: Explosão. Vazamento. Dispersão. FDS.

\begin{abstract}
Liquefied petroleum gas (LPG) is a mixture of propane and butane and is an important fuel for the operation of heating systems and in residential and industrial furnaces for cooking food. The objective of this work was to carry out a case study of an explosion that occurred in the city of Vila Velha / ES, on May 31, 2018. A computational model was constructed using Fire Dynamics Simulator software. concentration of the gas in the region of the possible ignition source that caused the explosion. Results showed that with the LPG dispersion present in the cylinder in a time of approximately 1 hour and 40 minutes with a mass flow of $0.0007142857 \mathrm{~kg} / \mathrm{s}$ during a simulation of 14.400 second ( 4 hours), at the height of the driven switch before the explosion, the concentration of LPG was recorded at $2.0 \%$, within the limits of LPG explosiveness, reinforcing the hypothesis of accidental cause.
\end{abstract}

Keywords: Explosion. Leakage. Dispersal. FDS.

\footnotetext{
${ }^{1} 1^{\circ}$ Tenente do Corpo de Bombeiros Militar do Espírito Santo, Perito de Incêndio e Explosão, graduado em Química e Engenharia Civil, mestrando em Química. igor.cunha@bombeiros.es.gov.br.

${ }^{2}$ Major do Corpo de Bombeiros Militar do Espírito Santo, Perito de Incêndio e Explosão, graduado em Administração, mestrando em Gestão Pública. andre.lugon@bombeiros.es.gov.br.

${ }^{3} 1^{\circ}$ Tenente do Corpo de Bombeiros Militar do Espírito Santo, Perito de Incêndio e Explosão, graduado em Ciências Biológicas. bruno.bona@bombeiros.es.gov.br.
} 


\section{INTRODUÇÃO}

O gás liquefeito de petróleo (GLP) é uma mistura formada por moléculas com carbono e hidrogênio (hidrocarbonetos) de três a quatro átomos de carbono, que nas Condições Normais de Temperatura e Pressão (CNTP) encontra-se no estado gasoso, no entanto, ao ser resfriado e comprimido, pode ser liquefeito. Constituído principalmente de propano $\left(\mathrm{C}_{3} \mathrm{H}_{8}\right)$ e butano $\left(\mathrm{C}_{4} \mathrm{H}_{10}\right)$, é incolor e inodoro em seu estado puro (sem adição de enxofre), apresentando uma queima limpa, quando comparado aos combustíveis mais pesados, tendo uma vasta aplicação nas áreas comercial, siderúrgica, petroquímica e agropecuária. (PETROBRAS, 2013)

O Brasil representa uns dos maiores mercados de GLP do mundo, sendo essencial para o desenvolvimento da economia do país, com uma comercialização anual estimada da ordem de 7.200.000 toneladas, sendo responsável pela geração de 350.000 empregos diretos e indiretos, tendo um faturamento anual de R $\$ 22$ bilhões (SINDIGÁS, 2014). O botijão do tipo P13 (13 kg) é o mais consumido no Brasil, sendo utilizado no consumo residencial para o cozimento de alimentos (ANP, 2017).

Com o passar dos anos, as instalações residências de GLP necessitam passar por reparos e substituição de seus componentes, sendo que o mau estado de conservação pode ocasionar uma liberação acidental do gás. Eles podem ser perigosos, especialmente em ambientes confinados com restrição na ventilação. $O$ objetivo deste trabalho foi investigar a dispersão ocorrida durante o vazamento de GLP em um botijão do tipo P13 em um ambiente residencial, com as dimensões e aberturas de ventilação de acordo com o estudo de caso realizado, identificando os riscos e a potencial chance de ocorrer uma explosão.

Espera-se que com o desenvolvimento desse trabalho, possamos potencializar a utilização da ferramenta FDS no auxílio a elucidação de vazamento de gases e entender o comportamento do vazamento de um botijão de gás em um ambiente residencial, 
Revista Científica do Corpo de Bombeiros Militar de Pernambuco

XVIII Seminário Nacional de Bombeiros - Foz do Iguaçu PR

Vol.04 N011 - Edição Especial XVIII SENABOM - ISSN 2359-4829

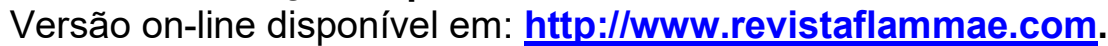

servindo como um ponto de partida para uma campanha educativa apresentando os riscos desse tipo de acontecimento.

\section{METODOLOGIA}

O trabalho consiste em um estudo de caso de uma explosão ocorrida no município de Vila Velha/ES, no dia 31 de maio de 2018, onde foi realizado a perícia de incêndio e explosão por uma equipe do Corpo de Bombeiros Militar do Espírito Santo. A partir dos dados obtidos in loco, foi construído um ambiente computacional, utilizando-se o Software Fire Dynamics Simulator (FDS), e simulado o vazamento do GLP no intuito de conhecer de que maneira ocorreu a dispersão do gás naquele ambiente, assim como identificar se a possível fonte de ignição, levantada pelo perito em sua análise, é compatível com a ocorrência da explosão.

As dimensões do ambiente computacional foram feitas com base no croqui do ambiente e a construção das aberturas e do posicionamento do botijão foi feita utilizando as fotografias feitas no dia do acidente, com isso, gerou-se um ambiente virtual no FDS, onde posteriormente foi parametrizado o vazamento do GLP.

O Fire Dynamics Simulator (FDS) foi desenvolvido pela primeira vez Instituto Nacional de Padrões e Tecnologia (NIST) para simular um fogo e a consequente fumaça. É um software gratuito que é capaz de resolver as equações de Navier-Stokes. Em uma grade retilínea tridimensional, o FDS emprega o método das diferenças finitas para estimar a derivação das equações conservativas de massa, momento e energia em um esquema de interação (McGRATTAN, 2017).

Além de ser desenvolvido para modelagem de fogo, o FDS também foi validado para a simulação de dispersão de gases e partículas por vários estudos. Cocchi (2014) realizou a modelagem de uma dispersão de gás pesado, utilizando o FDS, e compactou com dados experimentais encontrados na literatura, concluindo que o FDS pode ser utilizado para modelar liberação de gases pesados sob condições ambientais calmas, onde a dispersão é regida pela gravidade. Nos estudos de Brzezinska e colaboradores 
Revista Científica do Corpo de Bombeiros Militar de Pernambuco

XVIII Seminário Nacional de Bombeiros - Foz do Iguaçu PR

Vol.04 N011 - Edição Especial XVIII SENABOM - ISSN 2359-4829

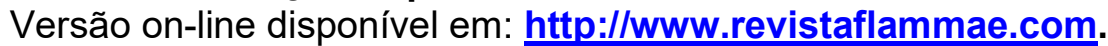

(2016) foi avaliada a liberação e dispersão de GLP com a utilização do FDS em um estudo de caso do vazamento de um tanque veicular de GLP na área de estacionamento de um parque, onde foram testados e avaliados diferentes sistemas de ventilação, verificou-se que os sistemas de ventilação com jato são muito mais eficientes no desbaste do gás abaixo dos limites explosivos do que os sistemas tradicionais.

\section{Explosão de GLP}

Uma explosão é a conversão súbita de energia potencial (química ou mecânica) em energia cinética com a produção e liberação de gases sob pressão. Esses gases, então, fazem trabalho mecânico, como, por exemplo, derrubam ou arrentam o recipiente no qual encontra-se confinado, estilhaça materiais próximos. (NFPA 921, 2013)

Para que ocorra uma explosão, são necessárias atingir alguns parâmetros, sendo eles: limite de inflamabilidade (Figura 01) e energia mínima de ignição (Tabela 01). A principal consequência das explosões de gás são quebras de materiais, espalhamento e onda de choque. A quebra e dispersão são causadas por um aumento de pressão no espaço onde o gás entrou em ignição. (DE HAAN; ICOVE, 2013)

Figura 01: Faixa de explosividade do GLP e seus componentes

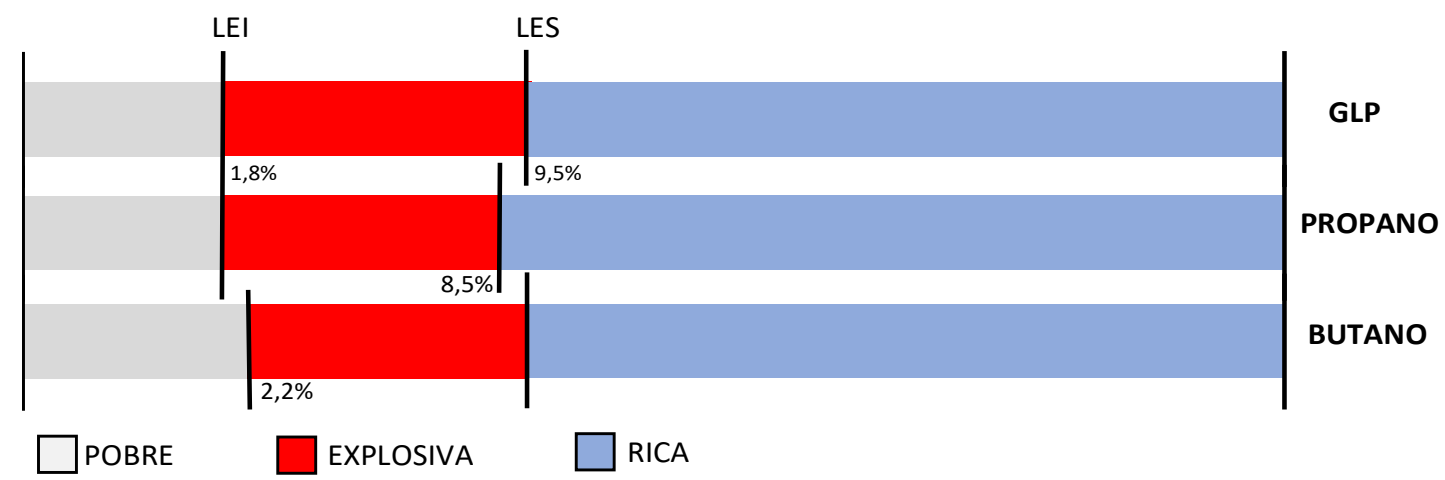

Fonte: Adaptado de FISPQ, 2015 
As explosões que ocorrem em mistura no ou perto do limite explosivo inferior (LEI) ou do limite explosivo superior (LES) de um gás ou vapor produzem uma explosão menos violenta do que aquelas próximas da concentração ótima. Isso ocorre porque a relação menor que a ideal de combustível e ar resulta em velocidades menores de chama, taxas mais baixas de aumento de pressão e pressão máxima mais baixa. Em geral, essas explosões tendem a empurrar a estrutura confinante, produzindo danos de baixa ordem. No entanto, há casos em que os níveis de mistura de combustível de misturas ricas são empurrados para fora de uma abertura de ventilação e se misturam com o ar ambiente, criando misturas inflamáveis e explosões potencialmente fortes. (NFPA 921, 2013)

Tabela 01: Energia mínima para ocasionar uma explosão

\begin{tabular}{cc}
\hline Gas/Vapor & $\begin{array}{c}\text { Energia } \\
\text { mínima de } \\
\text { Ignição (mJ) }\end{array}$ \\
\hline Acetileno & 0,02 \\
Butano & 0,26 \\
Etano & 0,24 \\
Heptano & 0,24 \\
Hexano & 0,248 \\
Hidrogênio & 0,018 \\
Metano & 0,28 \\
Metanol & 0,14 \\
Pentano & 0,22 \\
Propano & 0,25 \\
\hline Fonte: NFPA 921,2013
\end{tabular}

Dobashi (2017) descreveu as explosões de poeira e de gás em um ambiente não confinado a partir de um ponto de vista da propagação das chamas. Na pesquisa sobre explosão de gás, a turbulência da chama torna o comportamento explosivo mais perigoso, especialmente, a instabilidade da frente da chama torna-se efetiva na explosão de gás em larga escala. Já na explosão de poeira, o comportamento de propagação de chama depende fortemente da propriedade e tamanho da partícula. A análise é feita 
Revista Científica do Corpo de Bombeiros Militar de Pernambuco

XVIII Seminário Nacional de Bombeiros - Foz do Iguaçu PR

Vol.04 N011 - Edição Especial XVIII SENABOM - ISSN 2359-4829

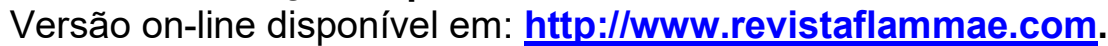

considerando os mecanismos de controle da reação química e da desvolatilização. $\mathrm{O}$ mesmo autor descreveu os parâmetros necessários para a ocorrência de uma explosão, apresentando conforme figura abaixo.

Figura 02: Parâmetros necessários para a ocorrência de uma explosão.

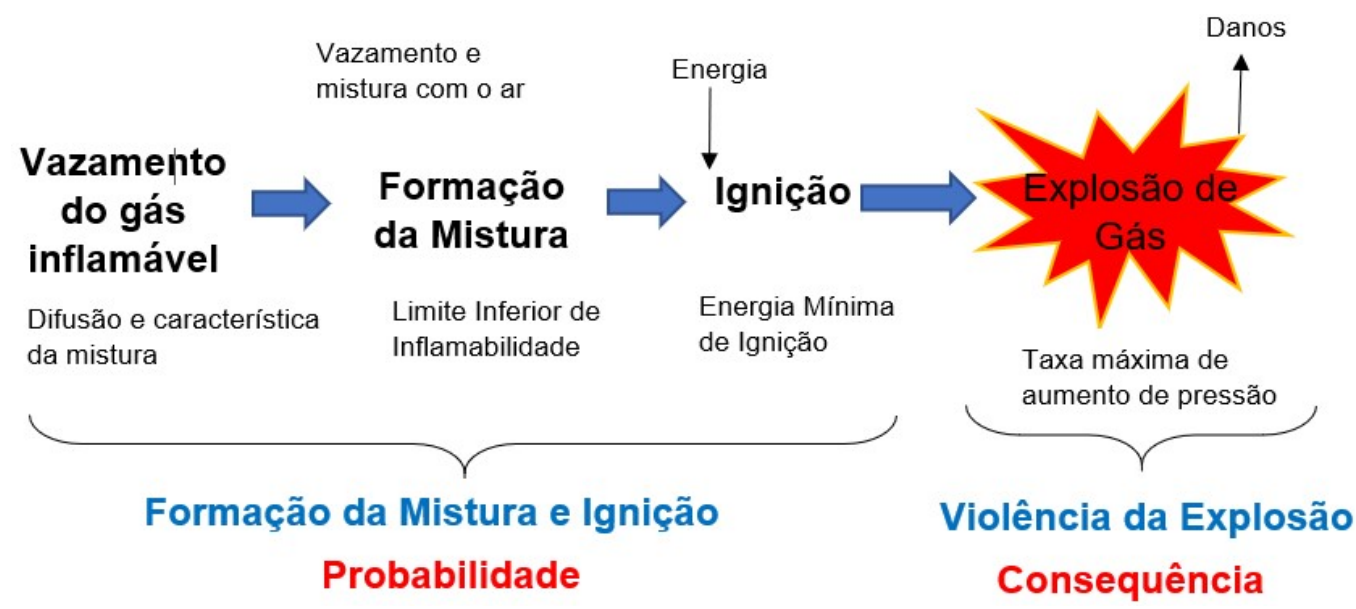

Fonte: Adaptado de Dobashi, 2017

\section{Parâmetros adotados}

Conforme os dados obtidos juntamente ao Departamento de Perícia em Incêndio e Explosão do Corpo de Bombeiros Militar do Estado do Espírito Santo, em um levantamento realizado pelo Perito de Incêndio e Explosão responsável pelo processamento da cena, foi gerado um possível cenário que acreditasse condizer com a realidade encontrada.

1) Com base na declaração obtidas no local da explosão, a vítima ficou fora de casa durante um período de aproximadamente 4 horas. Esse tempo foi utilizado como parâmetro para a duração da simulação, sendo definido o período de 3 horas e 40 minutos como o momento no qual a vítima chega em casa, abre a porta do quarto e aciona o interruptor da luz do quarto (potencial fonte de ignição); 
2) Adotou-se o para efeito de simulação, no intuito de simplificar a mistura do GLP, o propano, que é um dos gases presente na composição do botijão e apresenta uma densidade que reflete bem os parâmetros do GLP;

3) Durante a simulação, considerou-se que ocorreu a dispersão de apenas $10 \mathrm{~kg}$ de gás propano, considerando que o botijão encontrado na cena ainda estava com gás;

4) As aberturas inferiores das portas do quarto, sala e cozinha foram definidas respeitando a limitação do mesh (malha) utilizada para realizar a simulação. Para isso, foi feito um ajuste na área de escoamento do gás, que foi definida com as dimensões de $30 \mathrm{~cm}$ de comprimento por $10 \mathrm{~cm}$ de altura;

5) As janelas do quarto e da cozinha, foram mantidas abertas durante toda a simulação, tendo em vista as fotos retiradas após a ocorrência da explosão, que demonstraram o posicionamento das janelas e o relato feito pelo perito, da situação encontrada do ambiente;

6) As paredes do cômodo foram definidas como inertes, não existindo nenhuma interação com o gás;

7) A simulação ocorreu durante um tempo de 14400 segundos ( 4 horas), realizando a abertura da porta do cômodo no tempo de 12000 segundos (3 horas e 40 minutos);

8) Foram colocados 10 dispositivos para medir a concentração do gás liberado no ambiente. Desses dispositivos, 5 foram posicionados no interior do quarto, na região próxima ao interruptor da lâmpada, nas alturas de $0,1 \mathrm{~m} ; 0,4 \mathrm{~m} ; 0,8 \mathrm{~m}$; $1,0 \mathrm{~m}$ e $1,2 \mathrm{~m}$ e 5 dispositivos na região externa do quarto, nas mesmas alturas, próximo a porta de entrada do quarto. Com os dados obtidos, foi possível obter um perfil de concentração do volume do gás liberado no ambiente por tempo, em um ambiente onde está ocorrendo o vazamento do botijão (cozinha) e no ambiente no qual acredita-se que tenha sido a zona de origem da explosão ocorrida (quarto). 
Revista Científica do Corpo de Bombeiros Militar de Pernambuco

XVIII Seminário Nacional de Bombeiros - Foz do Iguaçu PR

Vol.04 No11 - Edição Especial XVIII SENABOM - ISSN 2359-4829

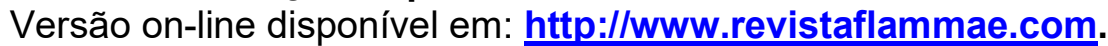

A geometria e dimensões do quarto foram feitas conforme croqui do ambiente elaborado pelo perito de incêndio retratando de forma fidedigna as características do local onde ocorreu a explosão.

Figura 03: Croqui do ambiente estudado.

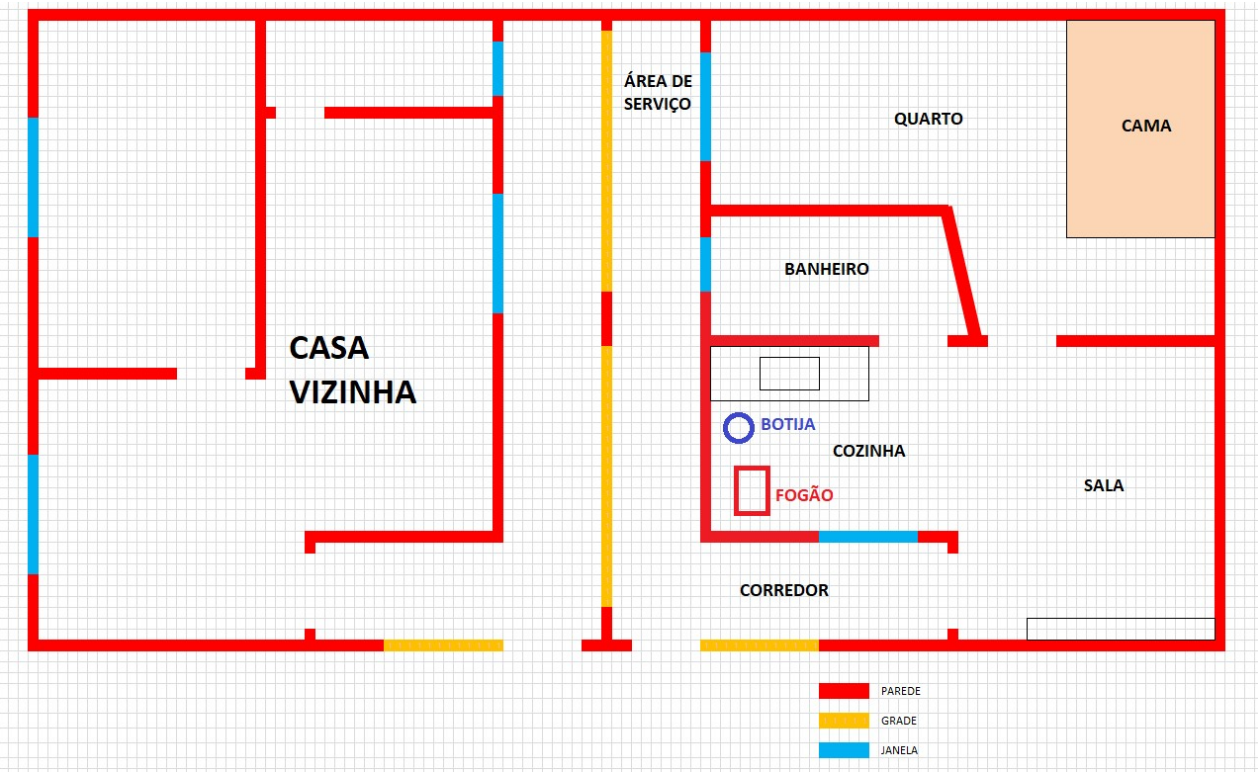

Fonte: DepPIE, 2018

\section{RESULTADOS E DISCUSSÕES}

Todos os parâmetros tomados para as simulações de liberação e dispersão de GLP foram baseados em resultados de validação do código FDS, obtidos em publicações sobre a temática. No cenário estabelecido, assumiu-se que ocorreu uma liberação contínua do gás presente no cilindro cheio (botijão P13) em um tempo de 4 horas. As concentrações do propano ao longo do tempo são apresentadas no Gráfico 01.

Gráfico 01: Variação da concentração de Propano, registrada pelos detectores instalados. (A) Interior do quarto. (B) Interior da cozinha. 
Revista Científica do Corpo de Bombeiros Militar de Pernambuco

XVIII Seminário Nacional de Bombeiros - Foz do Iguaçu PR

Vol.04 N011 - Edição Especial XVIII SENABOM - ISSN 2359-4829

Versão on-line disponível em: http://www.revistaflammae.com.

A)

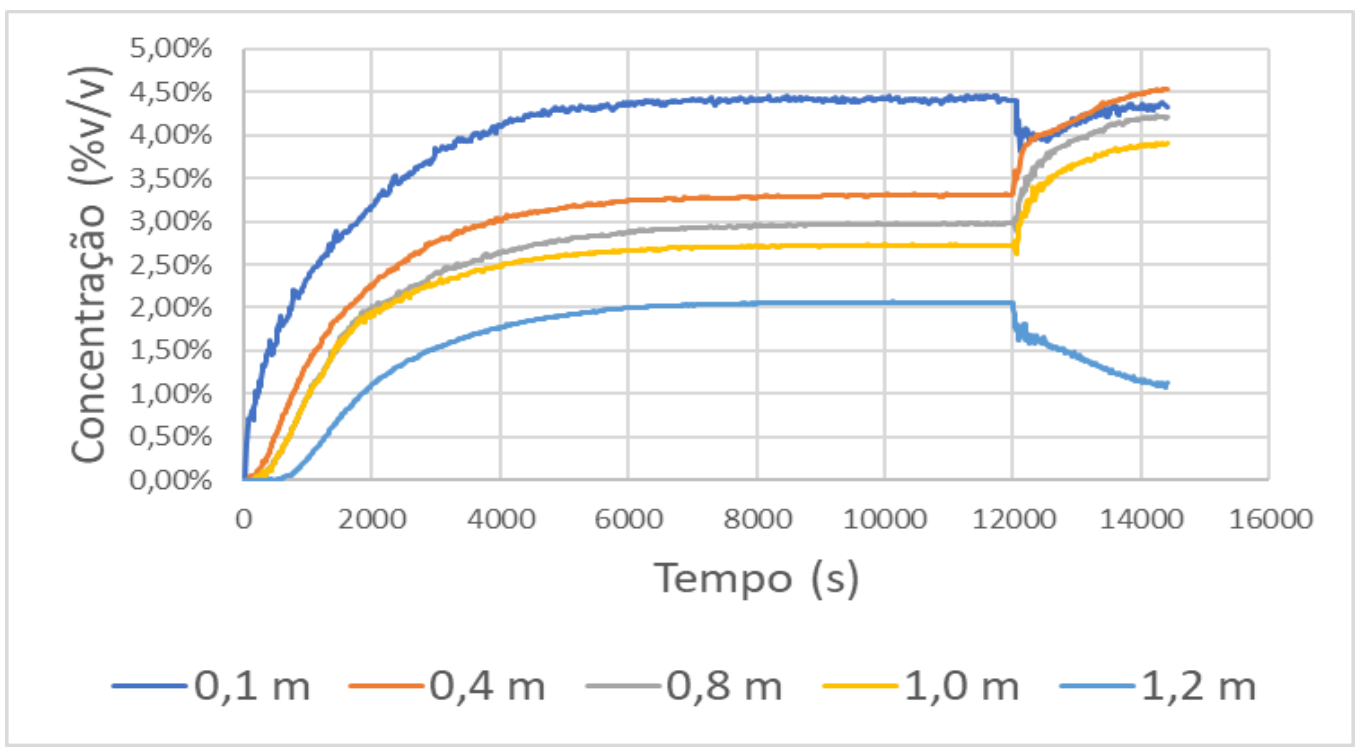

B)

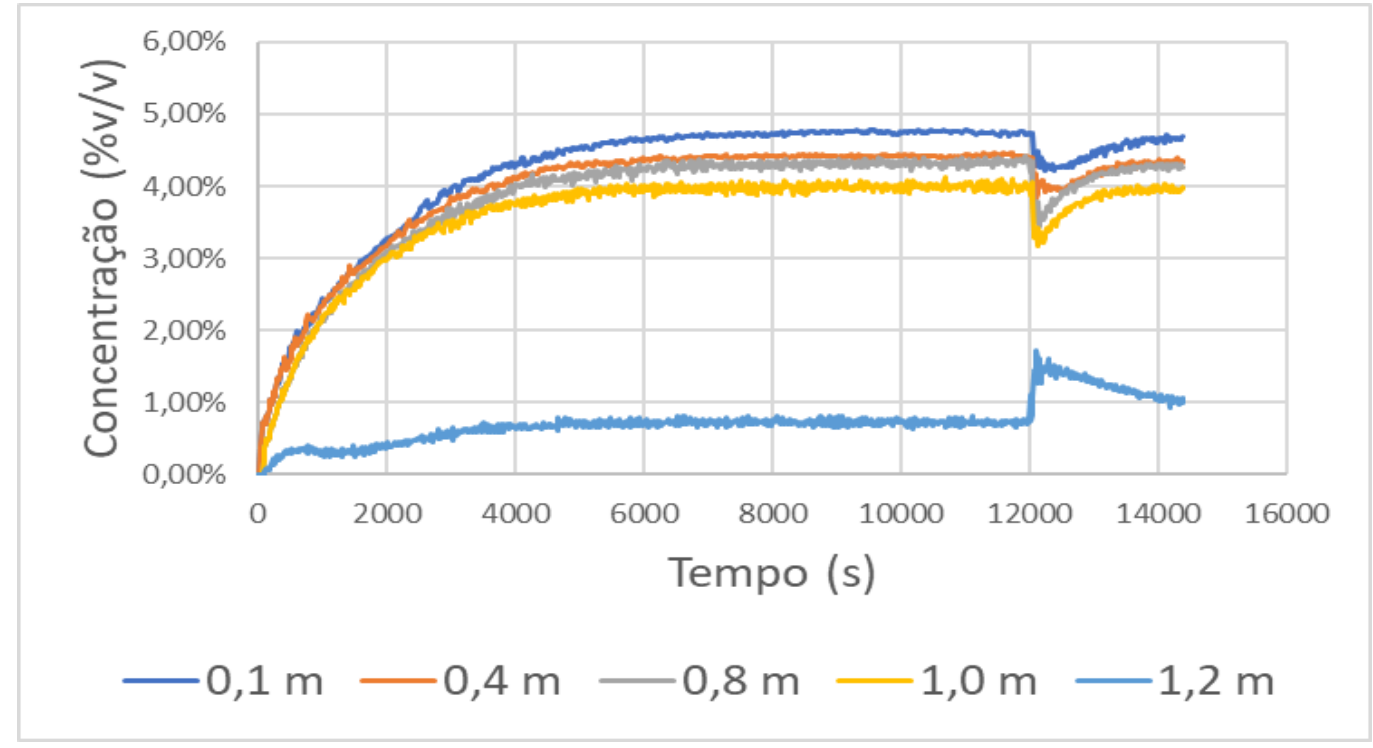

Fonte: Dados obtidos do FDS, 2018

No Gráfico 01, observa-se que nos detectores de $0,1 \mathrm{~m}$ a $1,0 \mathrm{~m}$ a curva da concentração pelo tempo demonstrou um comportamento bastante similar e mesmo com a porta do quarto fechada, a dispersão proporcionou um ambiente quase homogêneo entre a cozinha e o quarto, considerando-se as mesmas alturas estudadas. 
No tempo de 6000 segundos (1 hora e 40 minutos), o dispositivo posicionado a $1,2 \mathrm{~m}$ no interior do quarto, registrou uma concentração de $2 \%$ de volume em relação ao ar (dentro dos limites de explosividade), mantendo-se nessa faixa até o momento definido como de abertura da porta 12.000 segundos ( 3 horas e 20 minutos). No tempo de 12000s foi feita a abertura da porta, ocasionando um equilíbrio da concentração do gás da cozinha com o quarto, sendo observado pela queda da concentração registrada pelos dispositivos da cozinha e aumento da concentração registrada pelos dispositivos do quarto.

A possibilidade de explosão na cozinha foi registrada em 550 segundos no detector instalado a $0,1 \mathrm{~m}$ próximo ao botijão e a 750 segundos no detector instalado a $1,0 \mathrm{~m}$, permanecendo entre os limites de inflamabilidade durante todo tempo da simulação, no entanto, ainda na cozinha, não foi atingido os limites de inflamabilidade na altura de $1,2 \mathrm{~m}$, demonstrando que o escoamento do gás nesse ambiente para o exterior estava sendo mais eficiente que a capacidade de acumular o gás. No interior do quarto, o detector instalado a $0,1 \mathrm{~m}$ próximo a porta de entrada, registrou valores entre o LIE e LSE no tempo de 550 segundo e no detector instalado a 1,2m, a 4115 segundos permanecendo entre os limites de inflamabilidade durante todo tempo da simulação.

Com a ventilação utilizada durante a simulação, considerando que a dispersão do gás para o ambiente externo da residência pudesse ocorrer somente pela abertura feita na parte inferior da porta, observou-se que a massa do propano que se manteve no interior da casa estabilizou-se em 1,60 kg, conforme o Gráfico 02 , mesmo que com a vazão utilizada ao longo do tempo da simulação tenha liberado uma quantidade de 10 $\mathrm{kg}$ de gás propano no ambiente. Esse valor atingido correspondo ao equilíbrio estabelecido entre a vazão de liberação do gás pelo botijão com a vazão de escape do gás do ambiente. 
Revista Científica do Corpo de Bombeiros Militar de Pernambuco

XVIII Seminário Nacional de Bombeiros - Foz do Iguaçu PR

Vol.04 No11 - Edição Especial XVIII SENABOM - ISSN 2359-4829

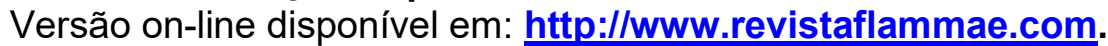

Gráfico 02: Variação da quantidade de Propano acumulado no ambiente ao longo do tempo

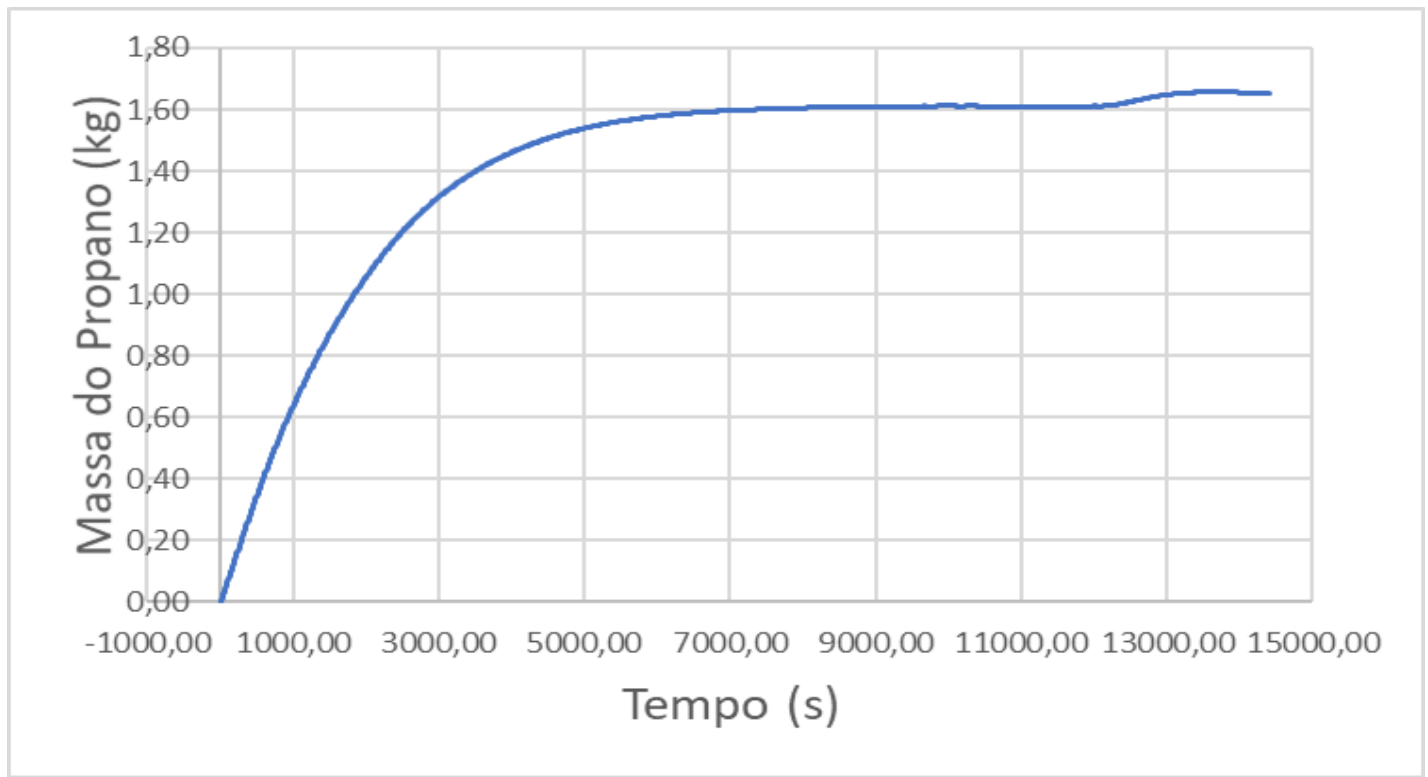

Fonte: Dados obtidos do FDS, 2018

A Figura 04 demonstra a dinâmica de vazamento do gás no cômodo, sendo observado a maior concentração de GLP na região perto da fonte de emissão. De maneira visual, observa-se que na região da cozinha, no tempo de 1200 segundos já é possível perceber uma quantidade de gás dentro dos limites de inflamabilidade, o que só é possível notar no quarto, em um tempo de 2400 segundos.

Em maiores distâncias da fonte de GLP, a concentração de gás atingiu níveis muito mais baixos e uma enorme diferença de concentração de gás entre detectores colocados em alturas de $0,1 \mathrm{~m} ; 0,4 \mathrm{~m} ; 0,8 \mathrm{~m} ; 1,0 \mathrm{~m}$ e $1,2 \mathrm{~m}$ foi observada. 


\section{Revista FLAMMAE}

Revista Científica do Corpo de Bombeiros Militar de Pernambuco XVIII Seminário Nacional de Bombeiros - Foz do Iguaçu PR Vol.04 No11 - Edição Especial XVIII SENABOM - ISSN 2359-4829 Versão on-line disponível em: http://www.revistaflammae.com.

Figura 04: Resultado da simulação no FDS demonstrando o perfil da concentração do gás.

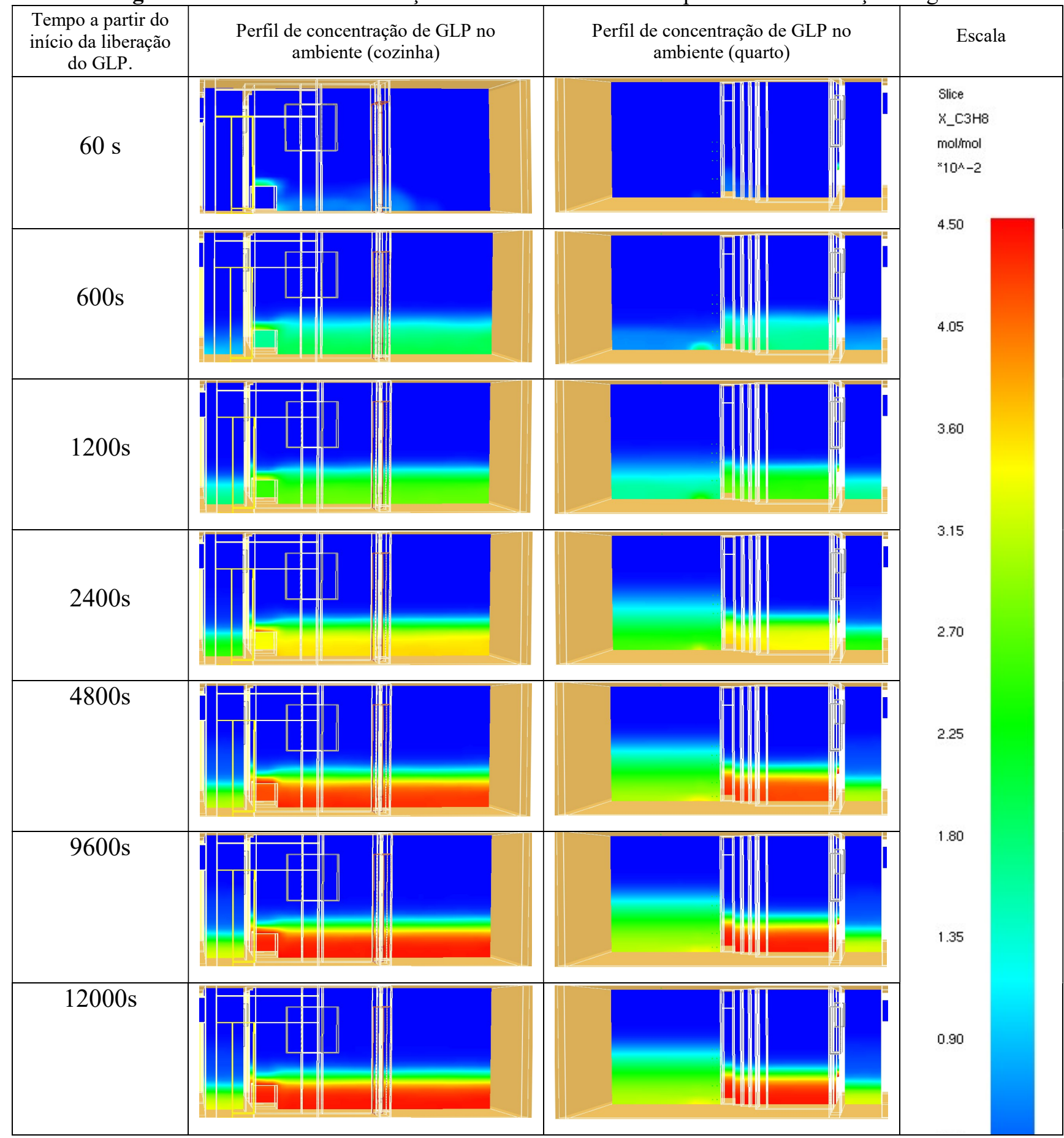


Revista Científica do Corpo de Bombeiros Militar de Pernambuco

XVIII Seminário Nacional de Bombeiros - Foz do Iguaçu PR

Vol.04 N011 - Edição Especial XVIII SENABOM - ISSN 2359-4829

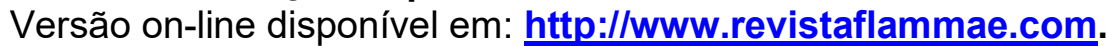



Fonte: Dados obtidos do FDS, 2018

Para fins de comparação, foi feita uma simulação utilizando-se os mesmos parâmetros acima apresentado, eliminando a ventilação da porta de entrada da casa, não permitindo que o gás escape para o ambiente externo, tendo os resultados dessa simulação são apresentados no Gráfico 02.

Gráfico 02: Variação da concentração de Propano, registrada pelos detectores instalados, desconsiderando a perda do gás para o ambiente externo da casa (A) Interior do quarto. (B) Interior da cozinha.

A)

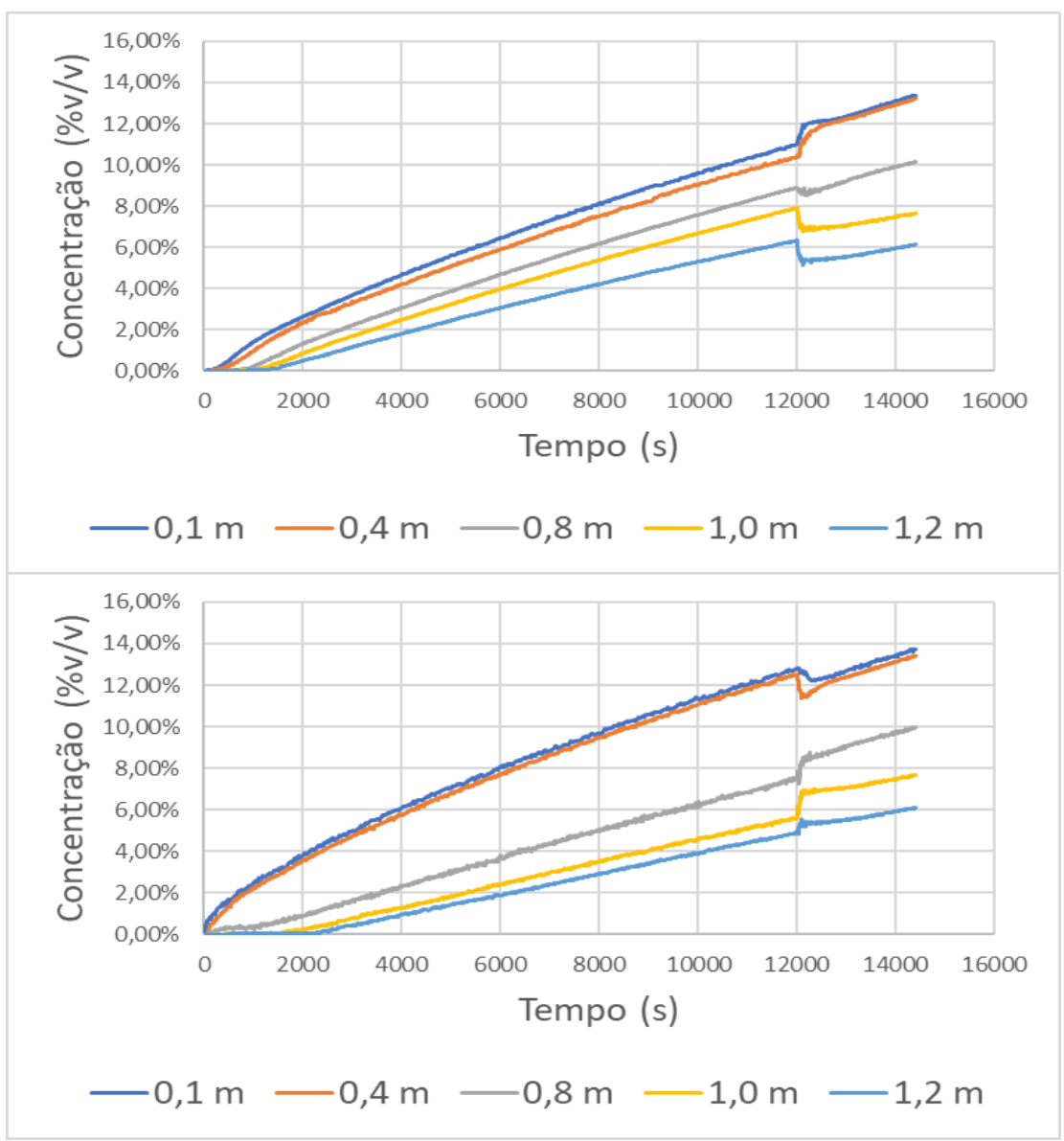

Fonte: Dados obtidos do FDS, 2018 
Em comparação ao Gráfico 01, observa-se que o crescimento da concentração se manteve de forma linear, tendo em vista que foi desconsiderado os efeitos da ventilação do ambiente externo, com isso, segue o fluxo de liberação de massa do gás propano que foi adotado para o botijão de gás. Em relação aos valores obtidos, observa-se que em ambos os dispositivos instalados para monitorar a concentração do propano, foram registrados valores dentro dos limites de explosividade, sendo que no dispositivo mais desfavorável no interior do quarto (1,2 metros) foi registrado um valor igual ao limite inferior de explosividade no tempo de 4018 segundos e no dispositivo mais desfavorável da cozinha, foi registrado no tempo de 1300 segundos.

No mesmo gráfico, é possível observar um ponto de inflexão no tempo de aproximadamente 12000 segundos, momento no qual é feita a abertura da porta. Aqueles valores que se encontravam superiores em relação ao do outro cômodo, tiverem um decréscimo, já aqueles valores que se encontravam inferiores ao outro cômodo, tiveram um acréscimo, devido ao equilíbrio que se estabeleceu entre os cômodos no momento que foi feita a abertura.

Em relação aos danos ocasionados no local da explosão, a Figura 05 traz um diagrama de fotos apresentando a localização de cada dano no cenário investigado. 


\section{Revista FLAMMAE}

Revista Científica do Corpo de Bombeiros Militar de Pernambuco

XVIII Seminário Nacional de Bombeiros - Foz do Iguaçu PR

Vol.04 No11 - Edição Especial XVIII SENABOM - ISSN 2359-4829

Versão on-line disponível em: http://www.revistaflammae.com.

Figura 05: Diagrama de fotos demonstrando o posicionamento dos danos decorrente da explosão

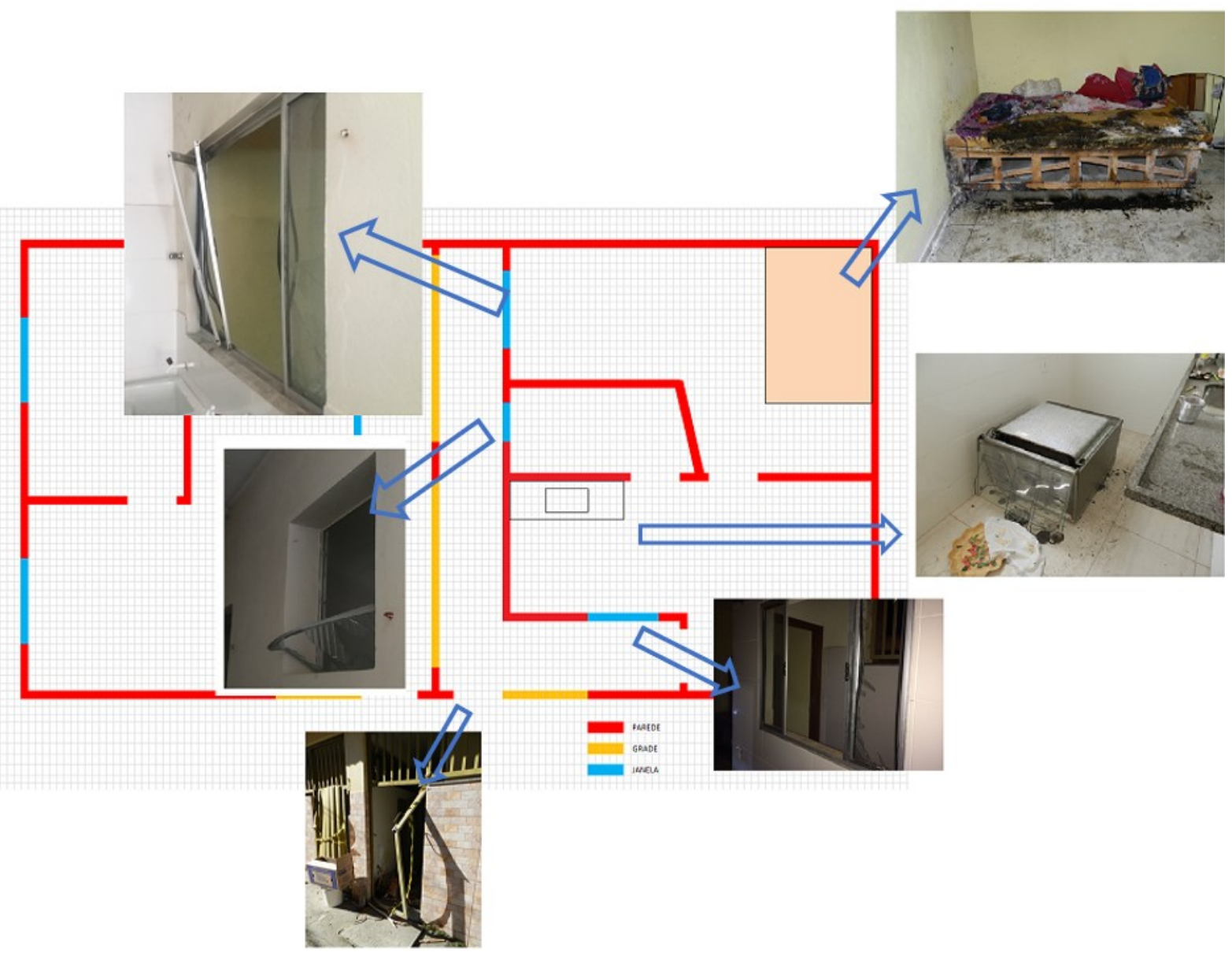

Fonte: DepPIE, 2018

Com base nos danos observados, juntamente com os ensinamentos presentes na NFPA 921, devido ao leve/moderado grau de destruição com baixo nível de queimas e devido ao sentido da quebra dos vidros e arrancamento parcial das janelas de alumínio, é possível inferir que a explosão se originou na região situada próxima a porta de entrada da cozinha para o quarto, assim como os limites de explosividade situavam-se próximo ao limite inferior no momento da explosão. 


\section{CONCLUSÃO}

Diante as informações apresentadas, conclui-se que o ambiente estudado apresentou as características necessárias para a ocorrência de uma explosão no ponto de vista estequiométrico das misturas de combustível com o ar, no entanto, é indispensável realizar uma análise do interruptor suspeito de ter ocasionado a ignição da explosão para verificar se existem indícios da ocorrência de qualquer fenômeno elétrico que estivesse relacionado ao fato e pudesse ratificar que se trata da fonte de ignição.

Conforme as imagens realizadas no local pelo perito de incêndio, confirma-se que a explosão ocorreu próximo ao limite inferior de inflamabilidade, tendo em vista o baixo nível de dano decorrente da velocidade menor da chama, reforçada pela concentração registrada no dispositivo instalado no local de suspeita da fonte de ignição.

A investigação da dispersão do gás por meio de simulação computacional demonstrou ser um importante recurso para conhecer o caminho percorrido pelo gás, considerando suas características físico-química e auxiliar na elucidação das causas dos incêndios e explosões, no entanto, é fundamental o trabalho do perito no local da ocorrência, tendo em vista que as entradas do programa são baseadas nas observações realizadas pelo perito e nas hipóteses por ele levantada.

Por fim, nota-se que a dispersão dos gases sofre uma influência de acordo com as particularidades do ambiente, encontrando-se em um mesmo ambiente diferentes concentrações com base na altura, formato das paredes, aberturas de ventilação, posição da fonte etc. Dessa forma, além da aplicação feita nesse estudo, fica evidente que o software pode ser usado em estudos para predizer o posicionamento de detectores de gases, aumentando a eficiência desses dispositivos e prevenindo a ocorrência de explosões. 
Revista Científica do Corpo de Bombeiros Militar de Pernambuco XVIII Seminário Nacional de Bombeiros - Foz do Iguaçu PR

Vol.04 No11 - Edição Especial XVIII SENABOM - ISSN 2359-4829

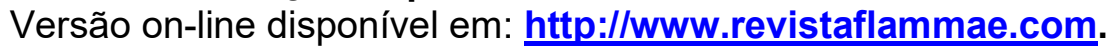

\section{REFERÊNCIAS}

ANP - Agência Nacional de Petróleo, gás natural e biocombustíveis. Gás Liquefeito de Petróleo - GLP. 2017. Disponível em: <http://www.anp.gov.br/petroleo-ederivados $2 / \mathrm{glp}>$ Acesso em: 12 jul. 2018.

BRZEZINSKA, Dorota; MARKOWSKI, Adam S. Experimental investigation and CFD modelling of the internal car park environment in case of accidental LPG

release. Process Safety and Environmental Protection, v. 110, p. 5-14, 2017.

COCCHI, Giovanni. Modeling instantaneous heavy gas releases with FDS5. Fire Safety Journal, v. 69, p. 89-98, 2014.

DE HAAN, John D.; ICOVE, David J. Kirk's Fire Investigation: Pearson New International Edition. Pearson Higher Ed, 2013.

DOBASHI, Ritsu. Studies on accidental gas and dust explosions. Fire Safety Journal, v. 91, p. 21-27, 2017.

FISPQ. Nome do produto: G.L.P. 2015. Disponível em: <

https://www.liquigas.com.br/wps/wcm/connect/a94a95004640d0be8ce7cddd2947447b/ GLP 2705 15.pdf?MOD=AJPERES\&CACHEID=ROOTWORKSPACEa94a95004640d0be8ce7cddd2947447b-kG6Kw2G> Acesso em: 12 jul. 2018.

McGRATTAN, Kevin et al. Fire Dynamics Simulator (version 6.5.3): User's guide. Washington: National Institute of Standards and Technology, 2017.

NATIONAL FIRE PROTECTION ASSOCIATION et al. NFPA 921: Guide for Fire \& Explosion Investigations. Technical Committee on Fire Investigations, 2013.

PETROBRAS. Gás Liquefeito de Petróleo: Assistência Técnica. Escola de Ciências e Tecnologias de Abastecimento - Universidade Petrobras, 2013.

SONNTAG, Richard E.; VAN WYLEN, Gordon J.; BORGNAKE, Claus.

Fundamentos da termodinâmica. Edgard Blücher, 2003.

SINDIGÁS - Sindicato Nacional das empresas Distribuidoras de Gás Liquefeito de Petróleo. Gás LP no Brasil. Volume 09. 2014. Disponível em:

$<$ http://www.sindigas.com.br/Estatistica/Default.aspx?cat $=8$ \&itemCount $=9>$. Acesso em: 12 jul. 2018. 